\title{
Meiose em Rhinocricus Padbergi Verhoeff, 1938
}

\author{
YONR G. P. DE CASTRO \\ Da Cadelra de Zoologia, Anatomia e Fisiologia da trscola \\ Buperior de Agricultura "Luiz de Queiros" \\ da Universidade de S. Paulo
}

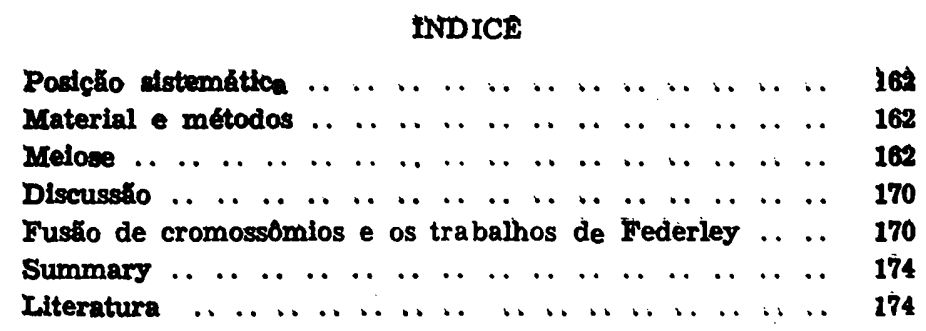


Posição sistemática - Miriápodo da ordem Diplópoda, subordsm Chilognatha, tribu Proterandria, familia Rhinocricidae.

Material e métodos: Os indivíduos foram obtidos no parque da Escola. A dissecaçăo fol felta sob Ringer; 3 individuos foram fixadas em Allen-Bauer e coloridos com hematoxilina e 11 foram fixados em San Felice e coloridos com Feulgen. Foram feitos esfregaços de vários indivíduas em aceto orceina sem prévio tratamento, enquanto outros foram submetidos à ação do $\mathrm{KCN}(2.1 / 1000 \mathrm{M})$ ou do $\mathrm{KNO}^{3}(10 \%)$, métodos preconizados para despiralização dos cromonemas, o primeiro por Oura (1936) e o segundo por Brieger (1939).

as machas apresentam um grande número de túbos testiculares, na parte ventral do corpo, ligados a um canal central que se abre entre o $2^{\circ}$. e o $3^{\circ}$. par de patas,

Meiose - Nas partes periféricas dos testículos mais velhos, ou mesmo na central dos jovens, aparecem grandes células com um novêlo cromático pálido encerrando um nucléolo esférico grande e diversos corpúsculos de tamanho variável, que se colorem fortemente pelo Feulgen, que são como veremos mais tarde formados pela reuniăo de partes heterocromáticas dos cromossómios. O novelo cromático val se tornando mais denso e contraindo-se para um lado do núcleo, apresentando o aspecto típico da sinizese. Nesta fase distinguem-se no novêlo as zonas heterocromáticas, fortemente coloridas e as zonas eucromáticas mais pálidas. Parece haver uma tendência das zonas heterocromáticas de se colocarem na periferia do núcleo. (Fig. 1).

Não há evidência de cromossômios sexuais.

Progredindo a melose, aparecem no núcleo, as cromossómias pareados, alguns com abertura mediana, um ou dois em forma de anel, e finalmente cordరes com as extremidades bem espêssas, forma essa que parece ser posterior às primeiras. (Fig. 2).

Continuando a contração, as cromossômios entram em metáfase com 0 aspecto característico de bivalentes, apresentando medianamente uma parte mais fina, examinadas em vista lateral. (Fig. 3). Em vista polar, mudando-se o foco, contam-se 10 pares de esferas superpastas. (Fig. 4). Alguns bivalentes progridem na meiose mais rapidamente que as outros, sendo mui- 
to comum encontrarem-se células com o fuso formado, e alguns bivalentes fora do plano equatorial, ainda năo orlentadas para a divisão; alguns bivalentes entrando em anáfase antes dos outros, dão, em vista polar, a impressåo de um número maior de cromassómios.

Os cromassomios entram em anáfase separando-se pela parte mais fina, apresentando-se nas anáfases mais adiantadas em forma de V. (Fig. 8 e 9).

Nas células bem favoráveis foi passivel contar, na metáfase, 10 pares de cromassomios em divisăo, no entanto nas espermatócitos de 2a. ordem foram encontrados 8,9 e 10 elementas. (Fig. 10).

Essa variação no número de unidades encontrada nos espermatócitos secundários tem uma explicação clara no comportamento dos cromassómios na primeira diviš̆o. Há uma tendência para uma fusáo dos bivalentes. Com relativa frequência, são encontradas células onde 2 cromossômios homólogos conjugados se fundem com outros 2, ou 4 bivalentes se fundem 2 a 2 . $\mathrm{Em}$ algumas células esses cromossomios parecem estar superpostas, mas em outras a fusăo é evidente. (Fig. 5). A figura 6 representa 2 pares de cromassómios nos quais realizou-se uma fusáo completa entre os năo homólogas de cada par, enquanto entre os outros dois a fusão năo fol perfeita; no entanto o conjunto dos outros dols cromossómios fundidos está ligado aos outros 2 por dols conectivas e năo apenas por um como acontece nas bivalentes simples. A figura 7 é uma diacinése com 8 bivalentes simples e dois fundidos. Como consequência destas fusões, os espermatócitos secundários apresentarão 9 ou 8 cromossôm!os, conforme a fusăo tenha sido apenas entre 2 pares ou entre 4 pares 2 a 2 . $\mathrm{Em}$ muitas células da 2a. divisáo é possivel, nas que apresentam 9 ou 8 cromossomios, identificar-se um ou dois elementos duplos. Um número maior de cromossómios fundidos na mesma célula pode ocorrer, pois foram encontradas também células de 7, 6 e até de 5 cromossómios, porém raramente.

Para verificar a correlaçăo entre o fenómeno da fusăo dos cromassômios e o aparecimento das metáfases secundárias de 8, 9 e 10 elementos, contei nas laminas correspondentes a 4 individuos, cujas cortes foram feitos com espessura de 20 a 30 microns, as células de 10,9 e 8 cromossómios, nas metáfases primárias e secundárias, abrangendo um total de 190 células e apliquel 0 teste $\mathbf{X}$. 


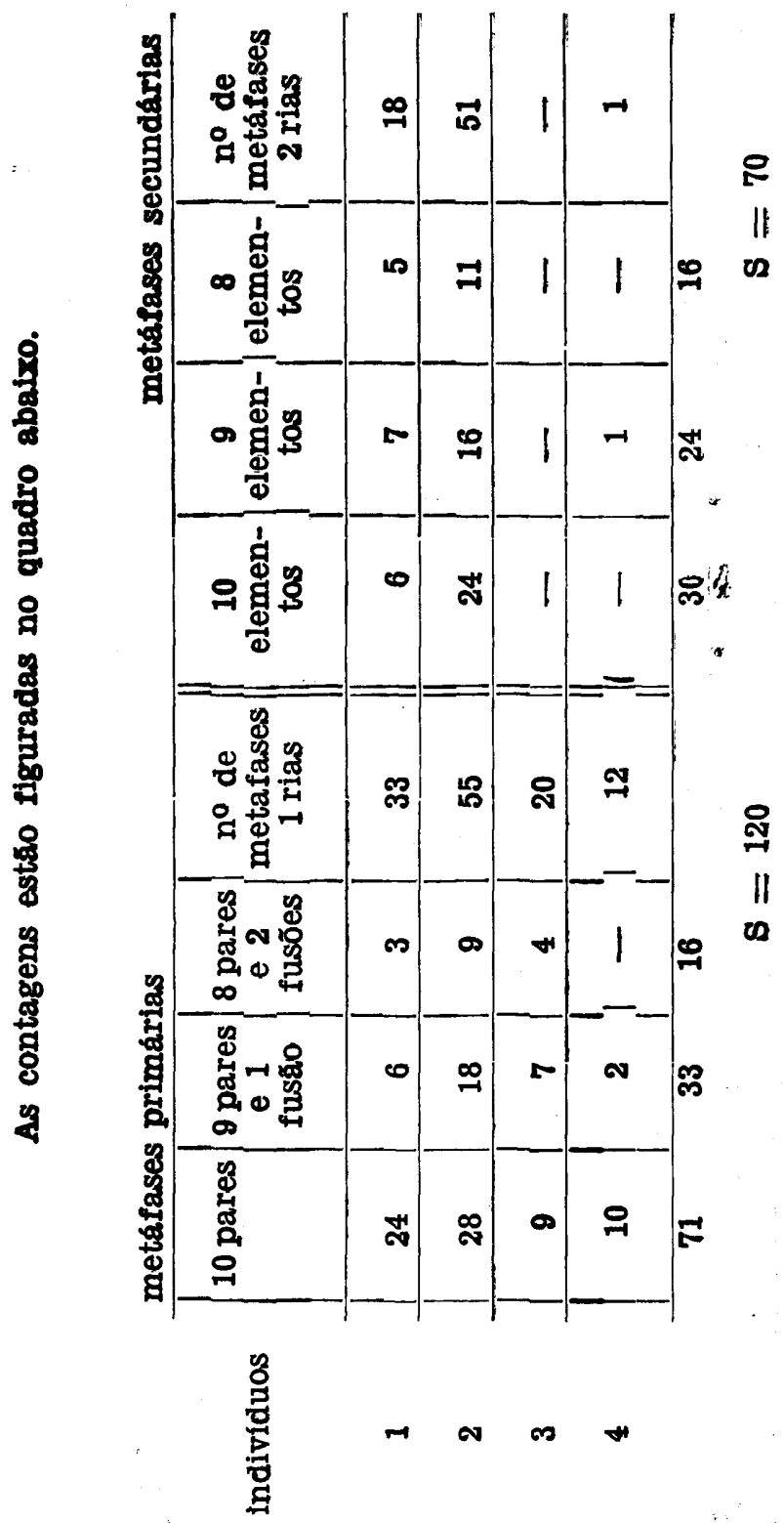


Aplicando o teste $\mathbf{X}^{2}$

$$
X^{2}=\frac{\text { (f. obs. }- \text { f. esp.) })^{2}}{\text { f. esp. }}
$$

Cálculo do "esperado": A frequência esperada foi calculada relacionando o número total de células com o número de metáfases primárias e o número de células que apresentam 10 cromossômios, 9 e 8 ou seja, nenhuma fusão, fusão de 2 bivalentes, e fusão de 4 bivalentes 2 a 2, respectivamente. Por exemplo, o primeiro esperado: O número total de células é 190, o número de metáfases primárias 120 , e o número de células sem nenhuma fusão, na primeira ou na segunda divisão, 101.

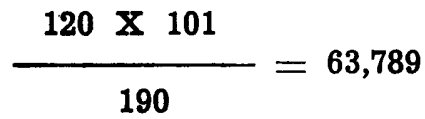
totais.

O quadro abaixo dá $\mathrm{O}$ valor de todos os $\mathbf{X}^{2}$, individuais $\mathrm{e}$

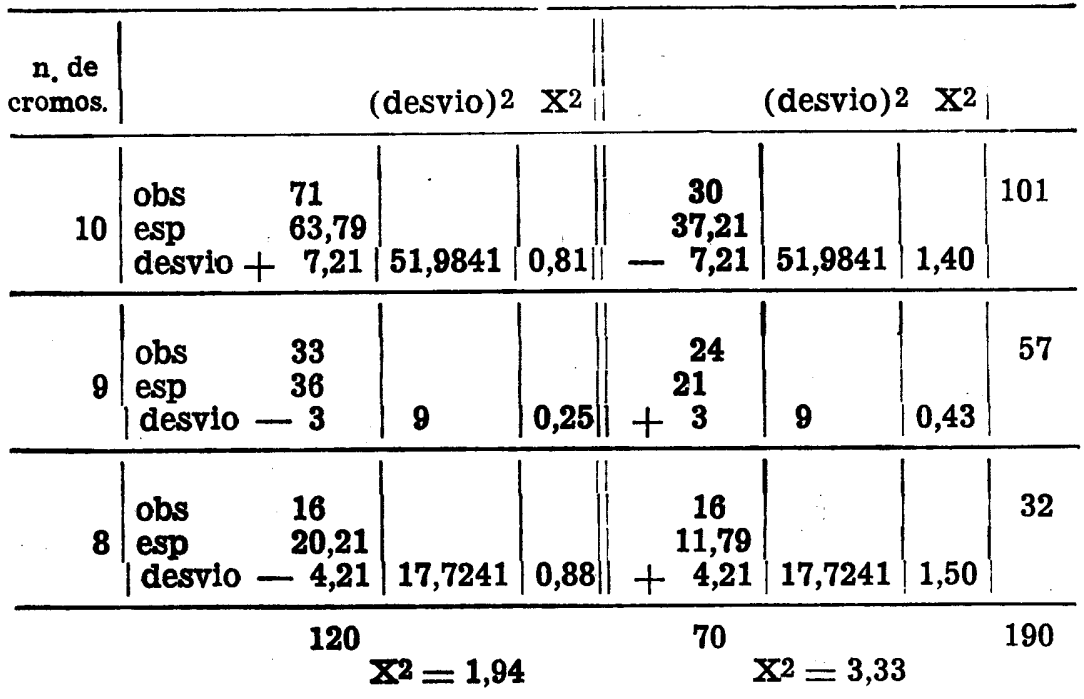

Para grau de liberdade $\mathbf{1}$, dos $\mathbf{X}^{2}$ individuais, temos os limites: 


$$
\mathrm{nf}=1 \quad \begin{aligned}
& 5 \%-3,8 \\
& 1 \%-6,6 \text { (Brieger, 1937) }
\end{aligned}
$$

Examinando-se as resultados de todos as $\mathbf{X}^{2}$ isolados, com esses valores, vemos que todos éles são insignificantes. Também $\mathrm{X}^{2}$ total, tanto para metáfases primárias como secundárias, comparados com os valores abaixo, correspondentes a $\mathrm{nf}=\mathbf{2}$, são insignificantes.

$$
\begin{array}{ll}
\mathrm{nf}=2 & 5 \%-6,0 \\
& 1 \%-9,2 \text { (Brieger, 1937) }
\end{array}
$$

O mesmo teste foi aplicado para a metáfase primária do indivíduo 1, e para a primária e secundária do individuo 2, isoladamente. A frequencla esperada fol sempre calculada relacionando o número total de células dos 4 individuos, 0 número de metáfases primárias ou o de metáfases secundárias, com, respectivamente, 0 número total de células sem nenhuma fusáo dos 4 indivíduos, com fusáo de dois bivalentes e com fusáo de 4 bivalentes 2 a 2.

Para 0 individuo 1,0 teste fol aplicado só para as metźfases primárias devido ao pequeno número de metáfases secundárias. As frequencias esperadas são as seguintes:

$33 \times 101$
$33 \times 57$

$$
\frac{3 \times 57}{190}=9,9
$$

\begin{tabular}{|c|c|c|c|}
\hline $\begin{array}{c}\text { n. de } \\
\text { cromossómias }\end{array}$ & & (desvio)2 & $x^{2}$ \\
\hline 10 & $\begin{array}{lc}\text { obs } & 24 \\
\text { esp } & 17,54 \\
\text { desvio } & +\quad 6,46 \\
\end{array}$ & 41,7316 & 2,38 \\
\hline 9 & 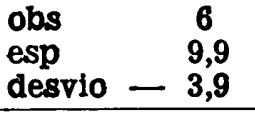 & 15,21 & 1,54 \\
\hline 8 & $\begin{array}{lc}\text { obs } & 3 \\
\text { esp } & 5,56 \\
\text { desvio } & -\mathbf{2 , 5 6}\end{array}$ & 6,5536 & 1,18 \\
\hline
\end{tabular}

$33 \times 32$

$$
\frac{33 \times 32}{190}=5,56
$$

Indivíduo 1 (só metáfases primárias) 
Tanto os resultados isolados (1 grau de liberdade) como o total (2 graus de liberdade) š́o insignificantes.

Também o mesmo resultado fol encontrado para as metáfases primárias e secundárias do indivíduo 2, como mostram os quadras abaixo.

Frequencia esperada :

$$
\frac{55 \times 101}{190}=29,24 \quad \frac{55 \times 57}{190}=16,5 \quad \frac{55 \times 32}{190}=9,26
$$

Indivíduo 2 (só metáfases primárias)

\begin{tabular}{|c|c|c|c|}
\hline $\begin{array}{c}\text { n. de } \\
\text { cromossomios }\end{array}$ & & (desvio) 2 & $X^{2}$ \\
\hline 10 & $\begin{array}{lc}\text { obs } & 28 \\
\text { esp } & 29,24 \\
\text { desvio } & -1,24\end{array}$ & 1,5376 & 0,0526 \\
\hline 9 & $\begin{array}{lr}\text { abs } & 18 \\
\text { esp } & 16,5 \\
\text { desvio } & +1,5\end{array}$ & 2,25 & 0,1400 \\
\hline 8 & $\begin{array}{lc}\text { obs } & 9 \\
\text { esp } & 9,26 \\
\text { desvio } & -0,26\end{array}$ & 0,0676 & 0,0073 \\
\hline
\end{tabular}

55

$$
\mathrm{X}^{2}=0,1999
$$

Frequencia esperada para as metáfases secundárias do individuo 2.

$$
\frac{51 \times 101}{190}=27,11 \quad \frac{51 \times 57}{190}=15,3 \quad \frac{51 \times 32}{190}=8,589
$$


Indivíduo 2 (só metáfases secundárias)

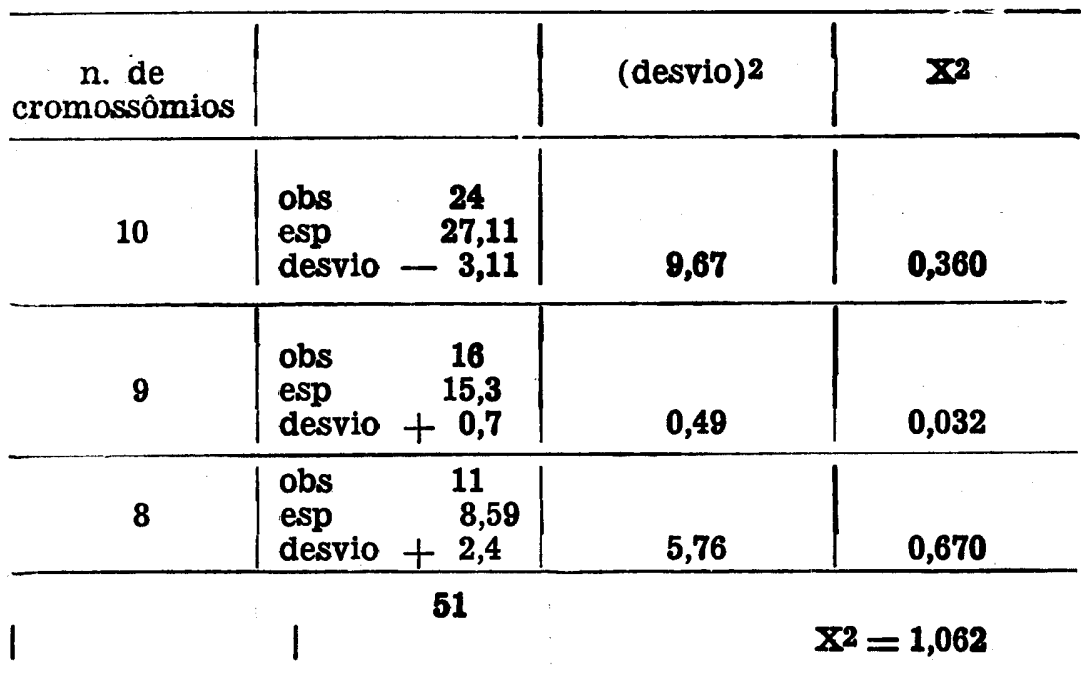

Todos os valores de $\mathrm{X}^{2}$ individuais assim como total estăo abaixo do limite correspondente a $5 \%$, são portanto insignificantes.

Essa fusão de cromossômios não homólogos já existe na literatura nos trabalhos de HARRY FEDERLEY e também de SEILERS e HANIELS, êstes últimos citados pelo primeiro, como veremos adiante.

A segunda divisåo nåo apresenta dificuldades, separando-se todos os cromossômios, pela parte mais fina, colocada no plano equatorial. (Fig. 11).

Foram encontradas algumas metáfases espermatogonais mas em nenhuma delas o número de cromossómios póde ser contado com exatidão, estando entre 18 e 20. Nas paredes de um testículo apareceram células em mitose e em uma delas, mais favorável, fol possível contar 20 cromossômios. (Figs. $12: 13)$.

Nas células em repouso de todo o corpo, e mesmo nos espematócitos que iniciavam a meiose foram notadas manchas Feulgen-positivas - cromocentros. Por sugestão de Dr. Rhoades experimentei tratar os testículos pelos métodos proprios 
para a dissolução da matriz e distensão dos cromatídios. Os métodos que deram melhores resultadas foram 0 tratamento pelo KNO3 a $10 \%$ (Brieger) durante 15 minutos a $1 / 2$ hora, e o tratamento pelo. $\mathrm{KCN}$, soluçto $2.10-3 \mathrm{M}$ (Oura), durante 1 a 2 horas.

Com estes métodas foram obtidas metafases com as cromassomios distendidos deixando perceber a espiral formada pelas cromatídias. Ainda por este tratamento as manchas Feulgen pasitivas, citadas atrás, as cromocentras, começaram a se desmanchar em espirals, ficando evidenciado que elas stho formadas pelas zonas heterocromáticas dos cromassomias. 0 numero e o tamanho delas é variável, e provavelmente estas zonas podem se fundir em outras malores. Deve ser um caso semelhante ao de algumas linhagens de milho, examinadas por MORGAN (1943). Aqul o material heterocromático é representado pelos "knobs", cromomeros, o organizador nuclear do cromossomio 6, e a regiáo adjacente ao centromero em alguns cromassomias, e ainda pelos cromassomias B. No nucleo intercinético, geralmente o organizador nucleolar se funde com as 2 nucléolos, os "knobs" e as cromossomios B dro origem cromocentros, e as regitoes heterocromáticas adjacentes 200 centromeros podem ser relacionadas com as áreas difusas de heterocromatina. Fol encontrada uma boa correlaça entre o numero de cromocentros no nucleo intercinético e o numero de "knobs" presentes nas cromassomias paquitenicos, como também entre o numero de cromossomios B, nas linhagens sem "knobs" distintos. Também nos nucleas salivares de Drosophila o cromocentro aparece como uma massa formada pela fusaro de tódas as regibes heterocromáticas vizinhas aos centromeros. (WHITE, 1945).

Além das células da linhagem germinal, aparecem nas testículos, já cheias de espermatozóides, células muito grandes com as cromassomias irregularmente distribuidas. Assim é que num fuso bem formado aparecem grandes massas cromossomicas distendidas em direçăo as polos, dando a idéla de uma tusăo de cromassomias. (Fig. 14). Estas células de divišro muito irregular nåo pertencem à linhagem germinal, e devem corresponder às células de nutriça descritas por Verhoeff na espermatogénese dos Quilópodas, citado por BUCHERL (1939). 


\section{DISCUSSAOO}

Na literatura ao meu alcance, encontrei apenas, em um livro de SCHRADER (1928) um pequeno resumo sóbre a determinaçáo sexual em Myriapoda. Asse autor conclui que seja provével que em Myrlapoda os machos sejam heterogaméticos e usualmente do tipo X0; no entanto em Rhinocricus padbergi isso nao se verifica.

Schrader coloca em Myriapoda, as myriapodas e as chilopodas. Aproveitel so a literatura referente a Myriapoda, porquanto hoje as Chilopodos formam uma classe a parte. Para Myriapoda esse autor cita os trabalhas de OETTINGER (1908, 1909) e SOKOLOFF (1914).

OETTINGER (1908, 1909). Estudou a espécie Pachyiulus varius Fab. Os espermatócitas passuem 24 autassomias e um sexocromossomio em forma de bastonete, bem maior que os autossomios. Os espermatócitos primários depois da sinapse apresentam 25 cromossomias. Năo houve portanto reduçáo. Na metáfase aparecem os cromossómios reunidos 2 a 2, formando os bivalentes.

SOKOLOFF (1914). Trabalhou em Polyxenus. Seu trabalho refere-se mals à formaçáo dos espermatozbides. A meiase é ortodoxa, sendo 8 o número haplólde de cromassomios. A primeira divisáo é equacional e a segunda reducional. Năo há reterencia a cromossomio sexual.

FUSAO DE CROMOSSOMIOS. OS TRABALHOS DE FEDERLEY

Uma afinidade secundária, resultando na associaçáo de dois cromossomios em um, uma fusão de cromassómias, já vem sendo apresentada desde 1932, por Federley, em seus trabalhos sobbre híbridos em Lepidoptera. Do cruzamento entre raças e entre espécies diferentes de Lepidópteros conseguiu Federley várias híbridas com uma diminuiçáa no número de cromossomios, o que êle atribui a uma tusáo.

Cruzando duas raças de Dicranura vinula, a fennica e a germanica, ambas com o número haplóide de cromossomios 21, 
Federley obteve hibridos, que na sua maioria năo apresentavam, na divisão de maturaçăo, 21 cromassomias como os pals, mas apenas 20 tanto na espermatogênese como na orogenese. Contagens de cromassômias feitas em 3 ovas de híbridos revelaram os numeros $\mathbf{4 0 , 4 1}$ e $\mathbf{4 2}$ acidentalmente distribuidos.

Do cruzamento entre duas espécies muito próximas de Sphingidae, uma fêmea de Deilephila galli Rott e um macho de Dellephila euphorbiae $L$, ambas com o número haplólde de cromossomios 29, foram obtidos 5 híbridos. Entre esses. 4 apresentaram como as pais o numero haplóide 29 e alguns poucos espermatócitos com 28 e 30 . Um dos hibridos apresentou a grande maioria das células com 28 cromassômias e algumas poucas com 27 e 29.

Outros casos de fusăo de cromassomios săo citadas por Federley em aligumas espécies de Nymphalineas e Lycaenideas. Em Nymphalineas aparece uma fusão de dois cromassómios nos oócitos primártios de algumas espécies. Assim é que Arginnis niobe, A. adippe e A. paphla, apresentam em regra geral 29 cromassomios nos machas e nas femeas as mais das vezes apenas 28 nos gametócitos, e entre éles um muito grande, quo muitas vezes mostra um estrangulamento que revela sua natureza composta, Na Argynnis pales $\mathrm{v}$. arsilache nem sempre parece realizar-se a fusáo, de modo que o macho apresenta o número haplóide 30 e fêmea 29 e 30 . Em Ly.caen dae, na espécle Lycaena astrarche o macho possui 23 cromossomios, dentre êles um muito grande, e a fêmea, a contrário, 24. Em Lycaena icarus, no oócito primário aparece um cromossômio grande unido a um menor, podendo-se reconhecer a fusáo por năo ser muito intima.

Procedendo a uma análise em várias famillas de Lepidópteros (Ropalóceros), Federley verificou que dentro de cada tamilia as espécies apresentavam sempre um número de cromossomias típico para quase todas, variando em algumas espécles para um numero pouco superior ou pouco inferior; no entanto, todas as familias têm um representante com um número bem menor de cromassomias. $O$ tamanho desses cromassomias é bem maior que o tamanho dos de todas as outras espécies da familia.

Reproduzo abaixo a representação gráfica feita pelo citado autor. 


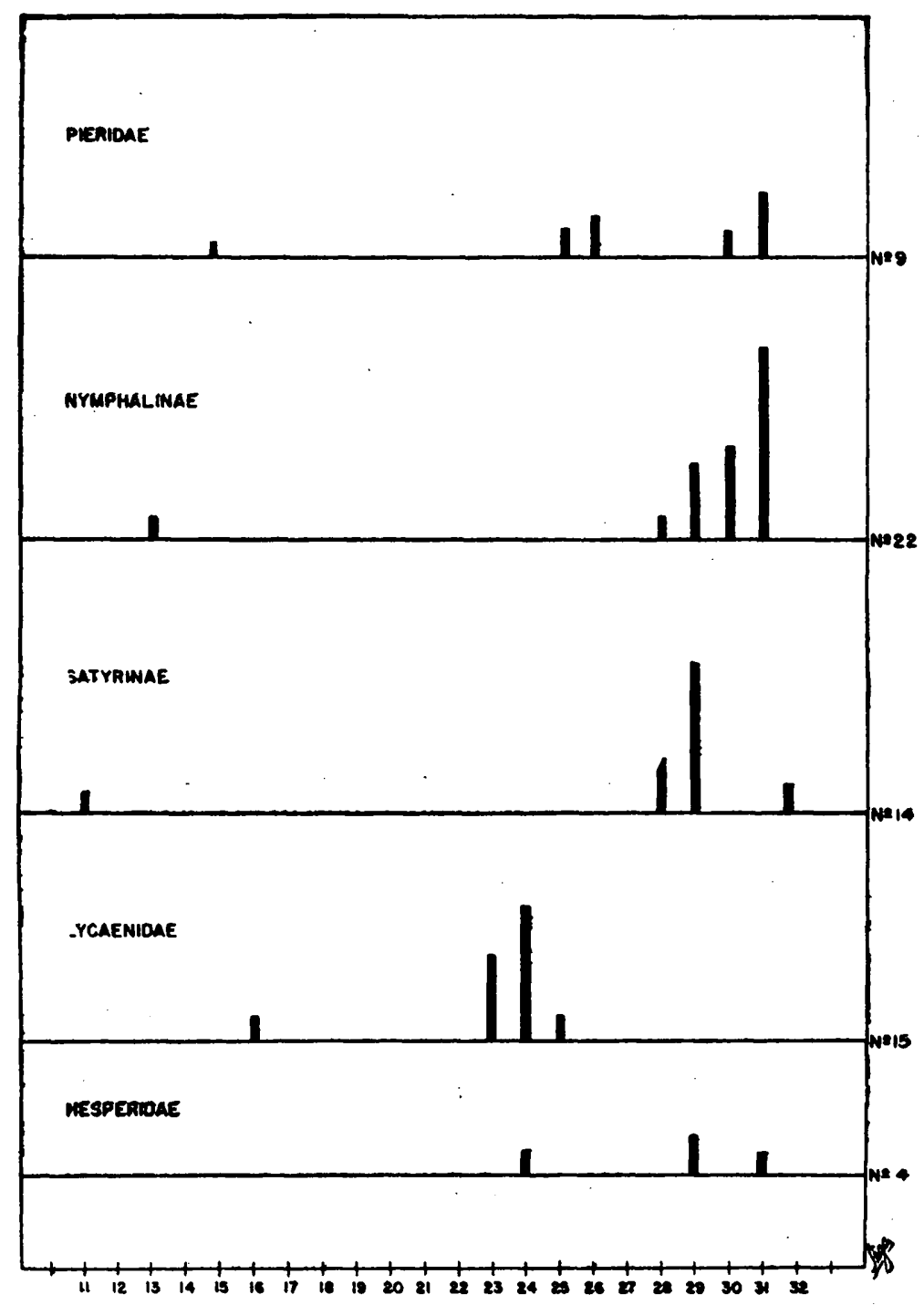


Entre as 9 Pleridae, 5 coincidem na classe 30-3I, tres na classe 25-26, e a espécle Pleris brassicae tem apenas 15 grandes cromassomias. Fm Nymphalinae, 20 inctädem na classe 29-31, uma espećle tem 28 cromassomias, e Argynnis ino o baixo número 13, porém cromassomios muito grandes. Entre as Satyrinae, 12 pertencem as classes 28-29, uma espécie possui 32 cromossomias Erebla medusa 11 cromossomias muito grandes. Imm Lycaenidae, de 15 espécies examinadas, 13 incidem na classe 23-24, uma tem 25 cromossomias e Zephyrus betuloe apresenta 16 grandes cromassomias. Também entre as Hesperidae a espécle Hesperia alveus apresenta 24 cromassomios enquanto as outras tres espécies apresentam 29 e 31.

A distribuiçáo das espécies nas familias mostra certa analogia. Im todas elas há um ápice mais ou menas pronunciado, onde se localizam quase todas as espécles. Mas todas as famillas apresentam uma espécle com um numero muito pequeno de cromassomios, sendo estes sempre muito maiores do que nos demais representantes da familia.

Outras familias apresentam ainda distribuiçấ análoga com relaçáo ao número de cromassómias. Entre as Saturnildeas e Geometrideas, há um áplce pronunciado em 30-31, 30 para as Baturnlideas e 31 para as Geometrideas, e uma espécle com um numero muito baixo, 13, em cada familla, e entre as Saturnildeas ainda uma com o número 19.

Para Federley, esta distribulçáo do número de cromassomias năo é apenas uma casualidade, mas a manifestaçăo de um processo que produz uma fusăo de cromassomias, apontando a favor dessa hipótese o considerável tamanho das cromassómios nas espécles que têm um pequeno número deles.

Outro exemplo que ainda esclarece a exatidáo da hipótese da fusăo de cromossomios é o cruzamento da Dicranura vínula fennica com D. vinula delavoeie, a primeira com 21 cromossomios e a segunda com 31. Federley só pode examinar um híbrido, notando que um numero nzo muito pequeno de espermatócitos mastra 21 cromassomlos e numerasissimas células da primeira diviša tem um numero de cromassomias que apenas excede 21 para poucos cromossómols. Incontestàvelmente dos 31 cromassomias de delavolel, dols ou mais se conjugam com um cromassomio de fennica.

Muito interessante também é o caso citado por Federley, do trabalho de SEILER e HANIEL (1921). Segundo esses autores a Lymantria monacha apressnta muito regularmente, tanto durante a espermatogênese como a oogenese uma fusáo de certas cromossomios formando um cromossomilo coletivo; as 
células somáticas sáo submetidas de novo a uma fragmentaçăo e retornam ao númeiro primitivo de cromassomios.

\section{SUMMARY}

In the present paper the behaviour of the ehromosomes in the spermatogenesis of the Myriapod Rhinocricus Padbergi Verhoeff, 1938 is studied.

The primary spermatocytes are provided with 10 independent bivalents which separate normally giving rise to equivalent secondary spermatocytes. No indication of sex chromosomes has been found. Fusion of two bivalents or of four, two by two, has been observed, giving origin to secondary spermatocytes with 9 and 8 chromosomes respectively, in which fused chromosomes could be discovered.

For analysing the facts the chomosomes of both, primary and secondary metaphases were separately counted from a total of 190 cells of four individuals and statistically treted. The $\mathrm{X}^{2}$-test gave insignificant results.

Twenty chomosomes were counted in somatic tissues.

The heterochromatic parts of the leptotene threads were usually arranged in the periphery of the nucleus.

In resting nuclel chromocenters can be observed in varyng number. Their chromasomal nature is revealed by the fact that when treated by KCN or KNOs they begin uncolling.

\section{LITERATURA}

BRIEGER, F. G. - 1937. Tabuas e Formulas para Estatística. Cia. Melhoramentos de S. Paulo - S. Paulo.

BRIEGER, F. G. - 1939. Estrutura dos cromassomios na melose. Jornal de Agronomia, 2: no 2.

BUCHERL, WOLFGANG - 1939. Os Quilopodas do Brasil. Memorias do Instituto Butantan. Vol. XIII.

FEDERLEY, HARRY - 1932. The Conjugation of the Chromasomes. Sixth International Congress of Genetics ..... 1: $153-164$.

FEDERLEY, HARRY - 1937. Fusion zweier Chromasomen als Folge Einer Kreuzung. Acta Soc. pro Fauna et Flora Fenn 60 . 
FEDERLEY, HARRY - 1938. Chromasomenzahlen Finnländischer Lepidopteren. 1 - Rhopalocera. Hereditas XXIV.

FHDERLLEY, HARRY - 1943. Zytologische Untersuchungen An Mischiligen Gattung. Dicranura b. (Lepidoptera). Hereditas 29

MORGAN, D. T. JR - 1943. The Formation of Chromocenters in Interkinetic Nuclei of Maize. Journal of Heredity XXXIV n. 7.

OETTINGER, R. - 1908. Zur Kenntnis der Spermatogenese bel den Myriapoden. Samenreifung und Samenbildung von Pachylulus varius Fabr. Zool. Anz. 33.

NETTINGER, R. - 1909. Zur Kenntnis der Spermatogenese bel den Myriapoden. Samenrelfung und Samenblldung Pachyiulus varius Fabr. Arch. Zellf. 3 (Citado por Sch:ader, 1928).

OURA, G. - 1936. A New Method of Unravelling the Chromonema Spirals. Zeitschrift für wisseschaftlich a Mikroskop:e und für mikroskopische Thechnik 53 536-537.

SCHRADER, F. - 1928. Die Geschlechtschromosomen. Gebrüder Borntraeger - Berlin.

SEILER, J. e HANIEL, C. B. - 1921. Das verschledene Verhalten der Chromosomen in Eireifung und Samenreifung von Lymantria monacha L. Z. f. Ind. Abst. und Vbgslehre. XXVII: 81-103.

SOKOLOFF, J. - 1914. Uber die Spermatogenese bel Polyxenus sp. Zool. Anz. XLTV.

WHITE, M. J. D. - 1945. Animal Cytology and Evolution. University Press. Cambridgミ 375 pags. 

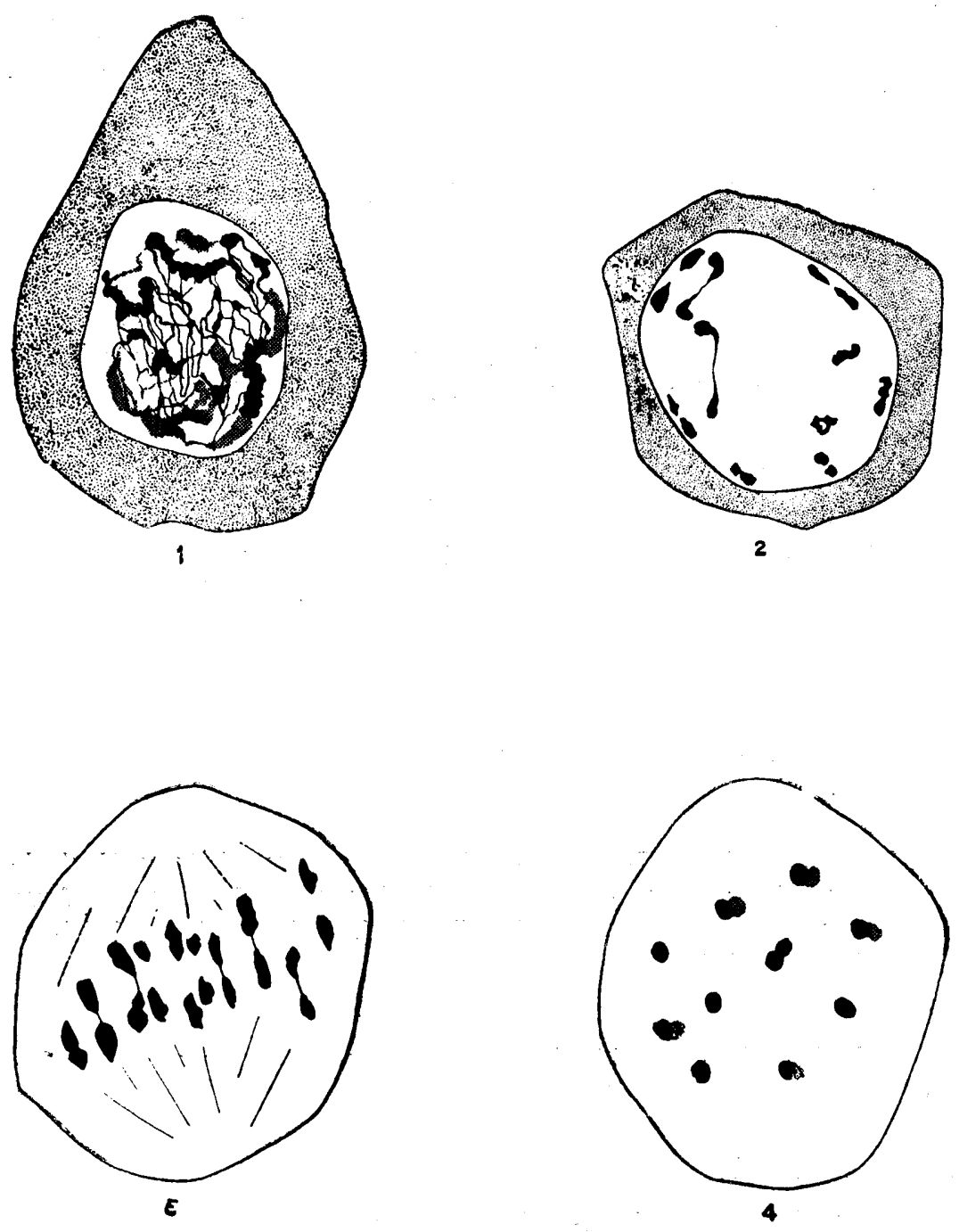

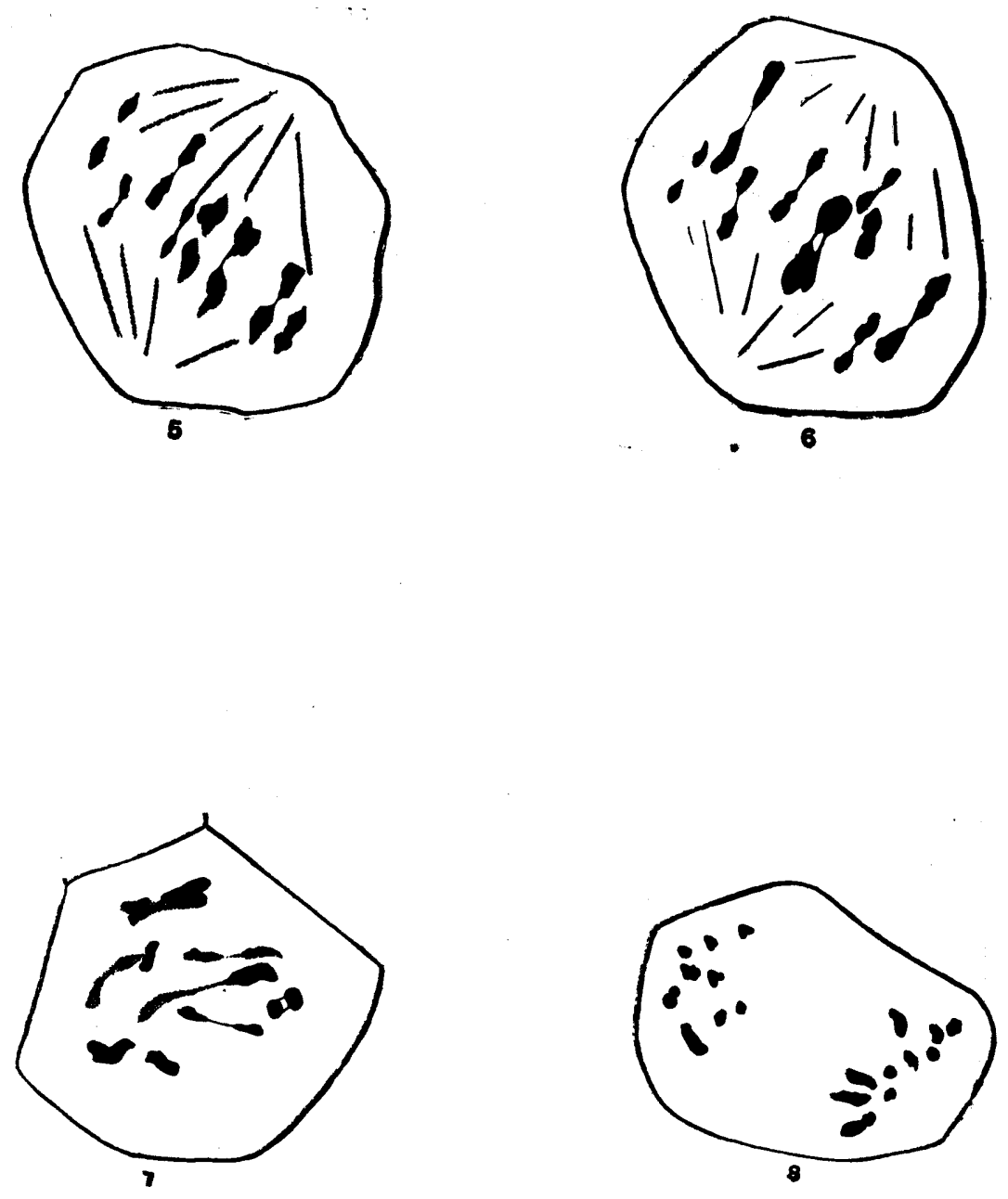

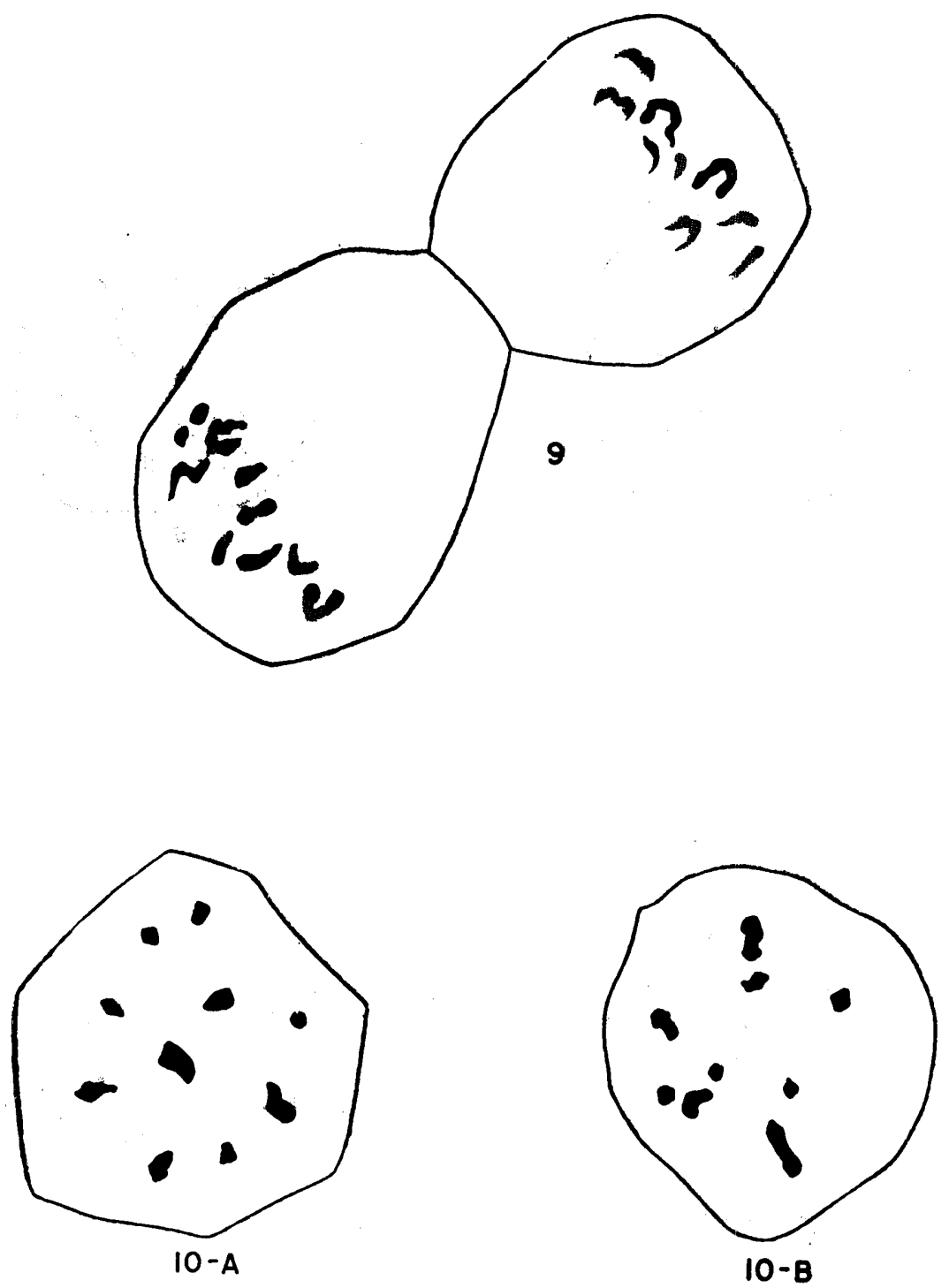

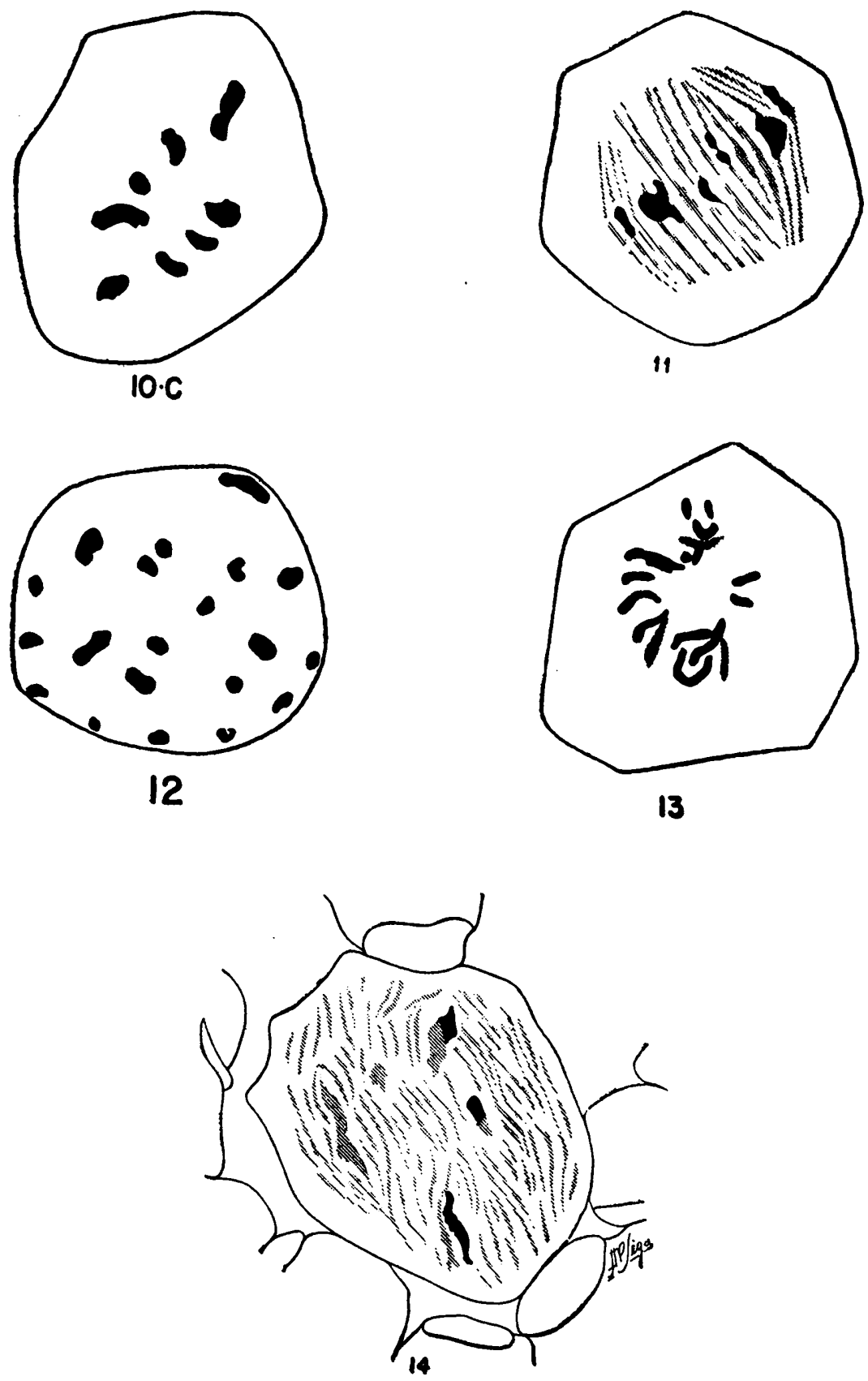
